\title{
Evidence-Based Dentistry among Iranian General Dentists and Specialists: A Knowledge, Attitude, and Practice Study
}

\author{
Surena Vahabi ${ }^{1{ }^{*},}$, Mahshid Namdari ${ }^{2}$, Mohammadreza Vatankhah ${ }^{3}$ and Kamyar Khosravi ${ }^{3}$ \\ ${ }^{1}$ Associate Professor, Department of Periodontics, School of Dentistry, Shahid Beheshti University of Medical Sciences, Tehran, Iran \\ 2 Assistant Professor of Biostatistics, Department of Community Oral Health, School of Dentistry, Shahid Beheshti University of Medical Sciences, Tehran, Iran \\ ${ }^{3}$ Dentistry Student, Shahid Beheshti University of Medical Sciences, Tehran, Iran \\ * Corresponding author: Surena Vahabi, Department of Periodontics, School of Dentistry, Shahid Beheshti University of Medical Sciences, Tehran, Iran. Tel: \\ +982122403010; Email: ivsure1@gmail.com
}

Received 2020 August 23; Revised 2020 August 30; Accepted 2020 September 15.

\begin{abstract}
Background: The use of evidence-based dentistry (EBD) as the integration of investigations and clinical decisions has been a focus of attention in recent years.

Objectives: The present study aimed to evaluate the knowledge, attitude, and practice of EBD among Iranian dentists in 2019.

Methods: A total of 140 self-administered questionnaires with 57 items were distributed among dentists in the 2019 exhibition of Iranian dentists. Moreover, 60 self- administered questionnaires were sent to five different dentistry schools in Iran. The analyses were carried out using the Chi-square test, independent samples t-test, and Pearson correlation.

Results: A total of 119 fully-responded self-administered questionnaires were analyzed in this study. The dentists attending EBD workshops obtained significantly higher scores of knowledge. The Cochrane Library, manufacturer's brochures, and evidence-based guidelines were used the least for clinical decisions. Consultation with colleagues, use of textbooks, and personal judgment were mostly utilized for clinical decisions. In addition, $93.3 \%$ of the participants stated sensible uncertainties in their clinical decisions. The most important barriers to EBD were the need for long discussions with patients, lack of skills in the critical appraisal of articles, and lack of motivation in dentists with the incidence rates of $62.2 \%, 62.2 \%$, and $39.5 \%$, respectively.

Conclusion: Due to the low levels of EBD knowledge among Iranian dentists, it is recommended to give further close attention to increasing the knowledge in this regard. However, their high enthusiasm for participation in EBD workshops and enhancement of EBD skills is promising.

Keywords: Attitude and practice, Dentist, Evidence-based dentistry, Knowledge
\end{abstract}

\section{Background}

The improvement of treatment methods in dentistry and selection of the best one are considered among the important goals in reforming the medical education systems (1). In addition to fundamental and suitable education, this issue requires strong evidence in the desired field to support the best treatment choice (2). The behaviors and treatment choices of patients and in turn dentist's response have significantly changed according to the increasing improvement of dental knowledge and equipment, increasing access to the internet (3), and high level of legal complaints against dentists (4).

The time-consuming nature of studies, especially randomized clinical trials, volume and time constraints of dental journals, which sometimes impose costs on researchers/non-academic physicians, and nature of dental treatments (not often life-threatening) can lead to a lack of strong and reliable evidence. This lack of information has led to some dental manufacturing and service companies to provide biased, unscientific, and inaccurate contents (5). Despite the introduction of evidence-based dentistry (EBD) since 20 years ago (6), a significant number of dentists still use their personal opinions in clinical decisions $(2,7)$.
Using the documentary evidence of credible articles, especially reviews and systematic reviews, is the solution suggested by the EBD approach to overcome the aforementioned problems while choosing the best treatment method. This type of treatment places the emphasis on the integration of prior knowledge, patient preference, and dentist experience (8). This approach has been successful in demonstrating the efficacy of Chlorhexidine and fluoride varnish in addition to the treatment of temporomandibular joint pain and other therapies (9).

A lack of useful and effective evidence (10), lack of EBD knowledge of dentists (11), and its low popularity among patients (12) are considered among the barriers making it difficult for the researchers to apply this approach. In contrast, using methods, such as improving the performance of dental researchers and their relationship with dentists, informing patients through insurance and medical organizations (8), and continuing education after graduation (13), can partially reduce the aforementioned barriers. Some studies have evaluated a low level $(40 \%>)$ of EBD knowledge (2, 14-16), and some others have estimated this value to be higher than $50 \%$ (17-22). In a study, different groups had varying degrees of EBD knowledge (23).

Two studies in two different Indian cities also 
showed that $92 \%$ and $73.3 \%$ of dentists made clinical decisions on their personal judgment $(2,7)$. A group of studies has referred to academic textbooks and articles used as the most fundamental sources of clinical decision-making $(24,25)$; however, the Cochrane Library has the least use in most articles $(2,14,18,21,26)$. In another study, individuals were more likely to decide on their actual knowledge level (14). With this background in mind, the present study evaluated the knowledge, attitude, and practice of EBD among Iranian dentists in 2019. The results may provide some information about EBD-associated knowledge and probable effective factors and identify problems that will be faced using possible approaches to improve the adoption of this method.

\section{Objectives}

The present study aimed to evaluate the knowledge, attitude, and practice of EBD among Iranian dentists in 2019.

\section{Methods}

In the present study, the Sabounchi et al.'s questionnaire was used as the main body of the utilized questionnaire the validity and reliability of which have been previously reported (14). The desired questionnaire was designed by the modification of five items and addition of five items. This 57-item questionnaire consists of the items on demographic information, individual's perception of his/her knowledge, his/her level of knowledge, and level of clinical implementation of EBD.

The questionnaires were distributed as a pilot study among 10 faculty members of the Dentistry School of Shahid Beheshti University of Medical Sciences, Tehran, Iran, and their comments were implemented to make the questionnaire easier to understand. The use of strong sources of evidence was scored according to a range of 0-35. The scores of the participants' EBD knowledge, their willingness to participate in the EBD workshop, and their attitudes were calculated using the score ranges of 4$18,0-10$, and 15-35, respectively.

The study subjects were dentists graduating from Iranian faculties. A total of 140 questionnaires were distributed among the interested dentists in the Exhibition and Congress of Iranian Dental Association in Tehran on April 25-26, 2019. Furthermore, 60 questionnaires were sent to the dentistry schools and clinics of Shiraz, Zanjan, Qazvin, Isfahan, and Azarbaijan provinces in Iran through e-mails. Finally, 129 questionnaires were collected. Then, data analysis was carried out using SPSS software (version 21) and Microsoft Excel (2016). The independent samples t-test, Pearson correlation, and Chi-square test were employed for statistical analyses.

\section{Results}

Out of 129 distributed questionnaires, 10 questionnaires were excluded due to incomplete data; therefore, 119 fully responded questionnaires were analyzed (with a response rate of $92.2 \%$ ). In this study, $53.8 \%$ and $46.2 \%$ of the respondents were male and female, respectively. The mean age of the study participants was $40.3 \pm 10.4$ years, with a possible age range of $24-67$ years. Totally, $77.3 \%$ of the respondents were general dentists, including 51 males and 41 females. Out of all the participants, $33.6 \%$ of them were reported with previous EBD selfstudy, and only $16 \%$ of them had attended EBD training workshops. Similarly, $63.9 \%$ of the subjects had internet access at work (Table 1).

\begin{tabular}{|c|c|}
\hline Characteristic & $\%$ (n) \\
\hline \multicolumn{2}{|l|}{ Age (year) } \\
\hline$<40$ & $52.1(62)$ \\
\hline $40-60$ & $46.2(55)$ \\
\hline$>60$ & $1.7(2)$ \\
\hline \multicolumn{2}{|l|}{ Gender } \\
\hline Male & $53.8(64)$ \\
\hline Female & $46.2(55)$ \\
\hline \multicolumn{2}{|l|}{ Educational level } \\
\hline Doctor of Dental Surgery & $77.3(92)$ \\
\hline Master's Degree & $22.7(27)$ \\
\hline \multicolumn{2}{|l|}{ Years since graduation } \\
\hline$<15$ & $54.6(65)$ \\
\hline $15-30$ & $38.7(46)$ \\
\hline$>30$ & $6.7(8)$ \\
\hline \multicolumn{2}{|l|}{ Clinical experience (year) } \\
\hline$<10$ & $39.5(47)$ \\
\hline $10-30$ & $52.9(63)$ \\
\hline$>30$ & $7.6(9)$ \\
\hline \multicolumn{2}{|l|}{ Teaching experience (year) } \\
\hline No experience & $76.5(91)$ \\
\hline$<15$ & $19.3(23)$ \\
\hline $15-30$ & $3.4(5)$ \\
\hline \multicolumn{2}{|l|}{ Research experience (year) } \\
\hline No experience & $75.6(90)$ \\
\hline$<15$ & $21.9(26)$ \\
\hline $15-30$ & $2.5(3)$ \\
\hline \multicolumn{2}{|l|}{ Previous knowledge of EBD } \\
\hline Yes & $33.6(40)$ \\
\hline No & $66.4(79)$ \\
\hline \multicolumn{2}{|c|}{ Participation in EBD tutorials } \\
\hline Yes & 16 (19) \\
\hline No & $84(100)$ \\
\hline
\end{tabular}

Figure 1 shows the frequency of participants' responses to the second part of the questionnaire on self-perceived knowledge. Out of 119 participants in this study, only $0.8 \%(n=1)$ of them had a very strong awareness of all of the items listed in this part of the questionnaire; nevertheless, $16.8 \%(n=20)$ of the respondents were completely unaware of all critical appraisal characteristics. The mean score of this part of the questionnaire was $12.32 \pm 5.29$ (min=6; max=30). There was no significant relationship between the mean scores with age and gender $(\mathrm{P}>0.05)$. Furthermore, increasing clinical experience 
was no evidence of an increase in the mean scores $(\mathrm{P}=0.15)$. However, there was a significant correlation between the mean scores with increasing education or research experience $(\mathrm{P}<0.001)$. In addition, volunteers previously participating in EBD workshops achieved better scores $(\mathrm{P}=0.002)$.

Among the available resources, the Cochrane Library, brochures of pharmaceutical companies, and evidence-based guidelines were the least frequently used resources. Furthermore, consulting with colleagues, using reference books, and relying on personal judgments were the most frequently adopted solutions, respectively. The mean score of using strong evidence resources, including evidencebased guidelines, Cochrane Library, original articles, and review articles, was $13.1 \pm 9.32$ ( $\min =0$; $\max =35$ ). There was also a correlation between this score and mean score obtained from the previous part of the questionnaire $(\mathrm{P}<0.001)$.
According to data analysis, $31.1 \%$ and $26.1 \%$ of the respondents had studied their most recent scientific article a week and a year ago, respectively. It was also observed that $16.8 \%$ of the participants studied two to three articles per week, and $6.7 \%$ of the dentists studied four to five papers per week. If there was a conflict between personal experience and results of the article, the respondents treated with articles in a different manner. Totally, 25.2\% ( $n=30)$ of the respondents ignored the article, and $26.1 \%$ $(n=31)$ of them considered the article the basis of their work; however, $48.7 \% \quad(n=58)$ of the respondents would like to evaluate the authenticity of the article.

A lack of motivation and mood, access to evidence, and skills in the critical review of the articles in addition to the need for long patient discussions were the most important barriers to the regular use of the evidence-based approach (Table 2). Additionally, the

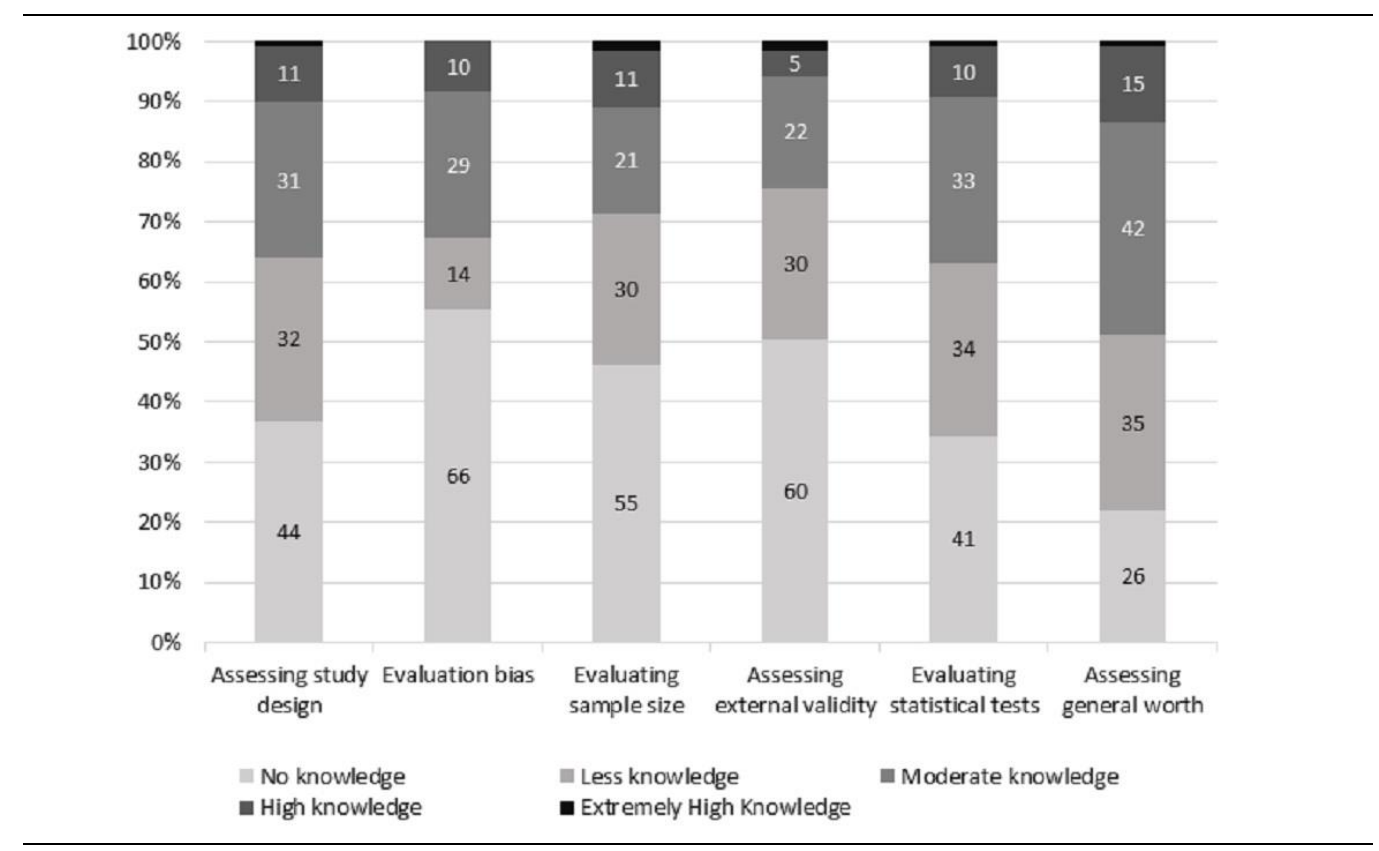

Figure 1. Percentage of self-perceived knowledge of critical appraisal skills in evidence-based dentistry (number of respondents written in each column portion)

\begin{tabular}{lc}
\hline Table 2. Most important barriers in regular use of evidence-based dentistry & \\
\hline Barrier & \% (n) \\
\hline Nature of dental treatments & $21.8(26)$ \\
$\quad$ No financial benefit using EBD & $38.7(46)$ \\
Difficulty using EBD for all treatments & $39.5(47)$ \\
$\quad$ Lack of motivation and patience & $16.8(20)$ \\
Quality and quantity of evidence & $33.6(40)$ \\
Lack of evidence & $20.2(24)$ \\
Lack of access to evidence & $29.4(35)$ \\
Great volume of evidence & $62.2(74)$ \\
Irrelevant evidence and clinical expertise & $37.8(45)$ \\
Patient's point of view & $37.8(45)$ \\
Need for long discussions with patients & $62.2(74)$ \\
Role of mass media in patients' knowledge toward EBD &
\end{tabular}




\begin{tabular}{|c|c|c|c|c|c|}
\hline Statement & $\begin{array}{l}\text { Strongly disagree } \\
\%(\mathrm{n})\end{array}$ & $\begin{array}{l}\text { Disagree } \\
\%(n)\end{array}$ & $\begin{array}{l}\text { No opinion } \\
\quad \%(n)\end{array}$ & $\begin{array}{l}\text { Agree } \\
\%(n)\end{array}$ & $\begin{array}{l}\text { Strongly } \\
\text { agree } \\
\%(n) \\
\end{array}$ \\
\hline 1- I need more training in EBD. & $1.7(2)$ & $9.2(11)$ & $16.8(20)$ & $31.9(38)$ & $40.3(48)$ \\
\hline $\begin{array}{l}\text { 2- In my opinion, EBD does not consider patient } \\
\text { views and ideas. }\end{array}$ & $14.3(17)$ & $21(25)$ & $55.5(66)$ & $3.4(4)$ & $5.9(7)$ \\
\hline 3- The EBD facilitates clinical decision-making. & $4.2(5)$ & $2.5(3)$ & $42(50)$ & $33.6(40)$ & $17.6(21)$ \\
\hline $\begin{array}{l}\text { 4- In my opinion, scientific evidence is } \\
\text { appropriate clinical guidance for practicing } \\
\text { dentistry. }\end{array}$ & $0.8(1)$ & $2.5(3)$ & $37(44)$ & $39.5(47)$ & $20.2(24)$ \\
\hline $\begin{array}{l}\text { 5- In my opinion, dental care or services can be } \\
\text { perfectly provided without the EBD approach. }\end{array}$ & $11.8(14)$ & $24.4(29)$ & $47.1(56)$ & $9.2(11)$ & $7.6(9)$ \\
\hline $\begin{array}{l}\text { 6- Types of provided dental services are } \\
\text { limited, and the EBD approach is not necessary. }\end{array}$ & $23.5(28)$ & $23.5(28)$ & $43.7(52)$ & $7.6(9)$ & $1.7(2)$ \\
\hline $\begin{array}{l}\text { 7- Evidence-based dental practice promotes the } \\
\text { quality of oral health care. }\end{array}$ & 0 & $0.8(1)$ & $40.3(48)$ & $36.1(43)$ & $22.7(27)$ \\
\hline $\begin{array}{l}\text { 8- In my opinion, limitation on accessing } \\
\text { scientific information sources in Iran is a great } \\
\text { obstacle to implement the EBD approach. }\end{array}$ & $5.9(7)$ & $15.1(18)$ & $39.5(47)$ & $19.3(23)$ & $20.2(24)$ \\
\hline $\begin{array}{l}\text { 9- The EBD is not a necessity as there are no } \\
\text { emergency cases in dentistry, and there is the } \\
\text { possibility of patient referral. }\end{array}$ & $37.8(45)$ & $21.8(26)$ & $33.6(40)$ & $5.9(7)$ & $0.8(1)$ \\
\hline
\end{tabular}

EBD concept had low popularity in the society based on the beliefs of $38.7 \%$ of the participants, and less than $10 \%$ of the patients had informed participation in the treatment strategy. Generally, $19.3 \%$ of the respondents also stated that the EBD concept was more popular and described further patient participation (up to $50 \%$ ).

The fourth part of the questionnaire included the items on the actual knowledge of EBD, in which the mean knowledge score of the participants was 9.95 \pm 3.69 according to data analysis ( $\min =4$; $\max =18)$. Out of all the respondents, only $3.4 \%$ $(n=18)$ of them correctly answered all the items; however, $52.1 \%$ of the respondents scored above the average level. There was a correlation between higher scores in this part of the questionnaire with more use of strong evidence-based resources, studying more articles per week, more experience of research, and more knowledge about the critical appraisal of articles $(\mathrm{P}<0.001$ for all the items).

The last part of the questionnaire deals with the dentists' level of attitude, and Table 3 tabulates the related information. In this regard, $72.2 \%$ of the participants stated the need for more training in this regard, and $93.3 \%$ of the respondents were hesitant to decide on daily treatments. Similarly, $58.8 \%$ of the subjects declared that the quality of oral health services was improved in case of using EBD. The mean score of willingness to participate in EBD workshops was $5.5 \pm 2.96(\min =0$; $\max =10)$. Moreover, the mean value of attitude was reported as 25.37 \pm 3.83 ( $\min =15$; $\max =35)$.

The results of Pearson correlation showed a statistically significant relationship between the mean scores of attitude with participation in EBD workshops, self-perceived knowledge score, years of research experience, frequency of using strong evidence-based resources, number of articles studied per week, mean score of actual knowledge, and willingness to participate in the workshop $(\mathrm{P}=0.043$, $\mathrm{P}=0.006$, and $\mathrm{P}<0.001$ for other items, respectively). However, there was no correlation between the mean score of attitudes with age and clinical experience $(\mathrm{P}=0.305$ and $\mathrm{P}=0.375$, respectively).

\section{Discussion}

Nowadays, patient satisfaction is very important among dentists, and their awareness of their rights and different treatment choices has also increased as much as their expectations (27). The assurance of continuing the improvement of patient care based on the progress achieved by new studies is the ultimate goal of EBD. However, the clinical application of this method has been more established in medicine. Moreover, although EBD is less developed in dentistry, it is rapidly progressing (28).

The results of the present study showed that despite the favorable attitude toward EBD, the knowledge level of EBD in Iran is low leading to the limitation of the clinical adoption of this method. However, the mean scores were higher among female respondents than the male subjects and significantly higher in specialized dentists than general dentists. Maybe, the greater number of general dentists (three times higher than the specialized dentists) is a reason for the large disparity between the two groups, which is one of the weaknesses of this study, such as answering the items by chance and reporting above the actual level.

In contrast, a high response rate $(92.2 \%)$ is a reason for the generalizability of the results. In a similar study, Haron et al. reported that $73.3 \%$ of clinical decisions were based on personal opinions, and the level of knowledge was low in this regard. Simultaneously, more than half of the respondents 
reported the clinical use of EBD. Attitude levels were also low, which is in contrast with the results of the current study (2).

In another study conducted in Bengaluru, India, despite the favorable attitudes of dentists toward EBD, there was a limited clinical application of the EBD approach due to a lack of access to resources (as the most important barrier). Totally, $92 \%$ of the participants relied on their personal opinions during decision-making, and $76 \%$ of them considered EBD to be synonymous with experts' opinions (7).

In another study, Rawat et al. showed lower levels of knowledge in the three study groups, including academicians, clinical practitioners, and academicians of dental practice (23). Among the groups, the third one had the highest level of knowledge. No insufficient time was also considered the most important barrier. Kumar et al. also conducted a study on the same three groups and observed that the knowledge level of clinical practitioners was significantly lower than the other two groups. Additionally, clinical practitioners preferred consultation with a colleague to the use of Internet databases (29).

In another study, Sabounchi et al. stated that $88.6 \%$ of the participants scored higher than the average level of knowledge, and individuals' perception of their knowledge was higher than the average in about half of the cases. Reference books (not recognized as the sources of strong evidence) and articles were identified as the most widely used evidence-based resources, and the Cochrane Library was the least frequently used source. Limited access to resources was considered the most important barrier to the application of EBD (14). Overall, participants' actual EBD knowledge was at a moderate level; however, their insight and willingness to use evidence-based methods was high $(14,30)$. In contrast with the results of this study, the knowledge level of medical residents was evaluated as moderate, and over two-thirds of them used consultation with their professors as a technique to answer their clinical questions (30).

The results of a study carried out on about 1,500 members of the American Association of Orthodontists showed that less than one-third of them had a complete understanding of EBD and were able to explain the used concepts in EBD. Moreover, more than half of the members were completely unaware of the Cochrane Library (28). According to multiple studies, the low level of knowledge among dental students opposes strong attitudes and limits the clinical use of the EBD approach (27, 28, 31-36).

Most students achieved higher mean scores in various sections of the questionnaire than the female respondents in a study by Dehghani et al. (31), which is inconsistent with the results of the present study. However, the aforementioned results are confirmed in a study conducted by Khami et al. (especially on the mean score of male students' awareness) (35). In the present study, there was no relationship between increasing students' semesters and higher mean scores; this finding is inconsistent with the knowledge score obtained in a study by Vatanpour et al. $(31,37)$.

The results of a study conducted on residents in various medical fields indicated that $53 \%$ of the residents, who were well acquainted with EBD, were also able to apply this approach in different treatments. Furthermore, classroom-based practice and workshops were referred to as methods leading to the widespread adoption of EBD (32). The results of another study also revealed that $82 \%$ of the medical residents of Mashhad University of Medical Sciences, Mashhad, Iran, had high attitude levels in this regard (38). Ali Shah et al. also stated that only $10 \%$ of participants permanently practiced EBD, and inadequate practice was identified as the most important barrier to the adoption of EBD. However, $88 \%$ of the subjects expressed their tendency to receive training in this domain (22).

Despite putting all efforts into comprehensive access to evidence-based resources, there are still many barriers in this regard resulting in the prevention of public clinical access, continuous physician practice, and patient use of optimal healthcare services, which are related to EBD. A systematic review identified the shortage of time, skill, and large number of patients as the most important barriers to the use of the EBD approach and called for policies on reducing the physicians' workload and providing them with pre-assessed evidence. This systematic review also referred to consultation with colleagues and reference books as the most frequently cited resources and Cochrane Library and up-to-date sources identified as the least frequently cited resources for dealing with clinical problems (36).

Vatanpour et al. considered the low effect of EBD education on indicators, such as knowledge, attitude, and access to EBD resources, and aimed to change the presentation, content, and continuous follow-up of next semesters and use this topic in clinical departments (37). Other studies revealed different results in this regard. Conflicting and equivocal evidence was considered the most important barrier to the adoption of EBD based on a group of orthodontists, and using evidence-based guidelines written by colleagues was regarded as the best EBD practicing method (28).

Kumar et al. also reported searching for and applying evidence-based summaries rather than usual skills as the best methods to replace the evidencebased approach with the personal decision-makingbased approach (29). Nieminen et al. reported that respondents had insufficient knowledge to critically evaluate an article (16). In addition, they stated that there is a need for changing the educational curriculum for further establishment of this method, 
which is similar to the results of a study by Moein Taghavi et al. (39).

\section{Conclusion}

The results of the present study revealed that the scores of participants' self-perceived knowledge were low, and $58 \%$ of the respondents were unaware of the items in the questionnaire. The Cochrane Library and consultation with colleagues were the least and most frequently used resources in case of having doubts about daily treatments, respectively. The actual knowledge level of the respondents was also moderate; however, the attitudes were reported at a high rate. Additionally, approximately $75 \%$ of the study participants expressed further practice in this field, which is considered a turning point in the maximum use of this method.

All of the aforementioned content necessitates the need for effective evidence-based training at lower levels of education to ensure the application of EBD in clinical practice in the medical science system on a daily basis. It is hoped that the level of EBD learning will be relatively high at the societal level according to the general positive attitude of dentists toward this topic.

\section{Acknowledgements}

The authors would like to express their gratitude to their colleagues, especially Dr. B. Farrokhzad, for their kind cooperation and support.

\section{Footnotes}

Authors' Contribution: Study concept and design by Dr. Vahabi; Acquisition of data by Mohammadreza Vatankhah and Kamyar Khosravi; Analysis and interpretation of data by Dr. Vahabi, Dr. Namdari, Mohammadreza Vatankhah, and Kamyar Khosravi; Drafting of the manuscript by Mohammadreza Vatankhah and Kamyar Khosravi; Critical revision of the manuscript for important intellectual content by Dr. Vahabi; Statistical analysis by Dr. Namdari; Administrative, technical, and material support by Dr. Vahabi; Study supervision by Dr. Vahabi

Conflict of Interests: There is no conflicts of interests.

Ethical Approval: Ethical code: IR.SBMU.DRC.REC. 1398.102

Funding/Support: The present study was financially supported by the School of Dentistry, Shahid Beheshti University of Medical Sciences, Tehran, Iran.

\section{References}

1. Winning T, Needleman I, Rohlin M, Carrassi A, Chadwick B, Eaton K, et al. Evidence-based care and the curriculum. Eur J Dent Educ. 2008;12(Suppl 1):48-63. doi: 10.1111/j.16000579.2007.00480.x. [PubMed: 18289268].
2. Haron IM, Sabti MY, Omar R. Awareness, knowledge and practice of evidence-based dentistry amongst dentists in Kuwait. Eur J Dent Educ. 2012;16(1):e47-52. doi: 10.1111/j. 1600-0579.2010.00673.x. [PubMed: 22251353].

3. Downes P. Putting it all together; dentistry and the Internet. Br Dent J. 2007;203(2):75-86. doi: 10.1038/bdj.2007.633. [PubMed: 17660777].

4. Thomas LA, Tibble H, Too LS, Hopcraft MS, Bismark MM. Complaints about dental practitioners: an analysis of 6 years of complaints about dentists, dental prosthetists, oral health therapists, dental therapists and dental hygienists in Australia. Aust Dental J. 2018;63(3):285-93. doi: 10.1111/adj.12625. [PubMed: 29862517].

5. Ballini A, Capodiferro S, Toia M, Cantore S, Favia G, De Frenza G, et al. Evidence-based dentistry: what's new? Int J Med Sci. 2007;4(3):174-8. doi: 10.7150/ijms.4.174. [PubMed: 17589569].

6. Richards D, Lawrence A. Evidence based dentistry. Br Dent J. 1995;179(7): 270-3. doi: 10.1038/sj.bdj.4808896. [PubMed: 7577182].

7. Rajagopalachari US, Puranik MP, Rajput S. Knowledge, attitude, and practices toward evidence-based dentistry among dentists of Bengaluru city. J Indian Assoc Public Health Dent. 2017; 15(3):239-43. doi: 10.4103/jiaphd.jiaphd_51_17.

8. Kao RT. The challenges of transferring evidence-based dentistry into practice. J Evid Based Dent Pract. 2006;6(1):1258. doi: 10.1016/j.jebdp.2005.12.011. [PubMed: 17138414].

9. McGlone P, Watt R, Sheiham A. Evidence-based dentistry: an overview of the challenges in changing professional practice. Br Dent J. 2001;190(12):636-9. doi: 10.1038/sj.bdj.4801062. [PubMed: 11453152].

10. Bero LA, Grilli R, Grimshaw JM, Harvey E, Oxman AD, Thomson MA. Closing the gap between research and practice: an overview of systematic reviews of interventions to promote the implementation of research findings. BMJ. 1998; 317(7156):465-8. doi: 10.1136/bmj.317.7156.465. [PubMed: 9703533].

11. Norman GR, Shannon SI. Effectiveness of instruction in critical appraisal (evidence-based medicine) skills: a critical appraisal. CMAJ. 1998;158(2):177-81. [PubMed: 9469138].

12. Greenhalgh T. How to read a paper: the basics of evidencebased medicine. New Jersey: John Wiley \& Sons; 2014.

13. Azarpazhooh A, Mayhall JT, Leake JL. Introducing dental students to evidence-based decisions in dental care. J Dent Educ. 2008;72(1):87-109. [PubMed: 18172240].

14. Sabounchi SS, Nouri M, Erfani N, Houshmand B, Khoshnevisan $\mathrm{MH}$. Knowledge and attitude of dental faculty members towards evidence-based dentistry in Iran. Eur J Dent Educ. 2013; 17(3):127-37. doi: 10.1111/eje.12019. [PubMed: 23815689].

15. Rajshekar SA, Kote KS, Nagesh L. Knowledge and attitudes towards evidence based dentistry among postgraduate students of two dental Colleges in Davangere City. J Indian Assoc Public Health Dent. 2011;9(18):761-5.

16. Nieminen $P$, Virtanen JI. Information retrieval, critical appraisal and knowledge of evidence-based dentistry among Finnish dental students. Eur J Dent Educ. 2017;21(4):214-9. doi: 10.1111/eje.12203. [PubMed: 27040996].

17. Spallek H, Song M, Polk DE, Bekhuis T, Frantsve-Hawley J, Aravamudhan K. Barriers to implementing evidence-based clinical guidelines: a survey of early adopters. J Evid Base Dent Pract. 2010;10(4):195-206. doi: 10.1016/j.jebdp.2010.05.013. [PubMed: 21093800].

18. Al-Ansari A. ElTantawi M. Factors affecting self-reported implementation of evidence-based practice among a group of dentists. J Evid Base Dent Pract. 2014;14(1):2-8. doi: 10.1016/j.jebdp.2013.11.001. [PubMed: 24581703].

19. Ciancio MJ, Lee MM, Krumdick ND, Lencioni C, Kanjirath PP. Self-perceived knowledge, skills, attitudes, and use of evidence-based dentistry among practitioners transitioning to dental educators. J Dent Educ. 2017;81(3):271-7. [PubMed: 28250032].

20. Ahad M, Gheena S. Awareness, attitude and knowledge about evidence based dentistry among the dental practitioner in Chennai city. Res J Pharm Tech. 2016;9(11):1863-6. doi: 10.5958/0974-360X.2016.00380.2. 
21. Gupta M, Bhambal A, Saxena S, Sharva V, Bansal V, Thakur B. Awareness, attitude and barriers towards evidence based dental practice amongst practicing dentists of Bhopal City. $J$ Clin Diagn Res. 2015;9(8):ZC49-54. doi: 10.7860/JCDR/2015/ 12814.6342. [PubMed: 26436047].

22. Ali Shah SM, Saquib KM, Omer SA, Mirza D, Amir A. Awareness, knowledge \& Practice of evidence-based dentistry amongst dentists in Karachi. Pak Oral Dent J. 2015;35(2):262-5.

23. Rawat P, Gosewami RP, Kaur G, Vyas T, Sharma N, Singh A. Knowledge, attitude, and behavior toward evidence-based dentistry among dental professionals in Jodhpur Rajasthan, India. J Contemp Dent Pract. 2018;19(9):1140-6. [PubMed: 30287718].

24. Rathod SI, Wanikar I, Raj A. Perception of dental professionals towards evidence based dentistry. J Educ Technol Health Sci. 2016;3(1):8-12.

25. Fedorowicz Z, Almas K, Keenan JV. Perceptions and attitudes towards the use of evidence-based dentistry (EBD) among final year students and Interns at King Saud University, College of Dentistry in Riyadh Saudi Arabia. Braz J Oral Sci. 2004; 3(9):470-4. doi: 10.20396/bjos.v3i9.8641753.

26. Navabi N, Shahravan A, Pourmonajem S, Hashemipour MA. Knowledge and use of evidence-based dentistry among Iranian dentists. Sultan Qaboos Univ Med J. 2014;14(2):e223-30. [PubMed: 24790746].

27. Apparaju V, Kale S, Srivastava N, Goswami RD, Kondaweei R, Pantaghada S. Role of evidence based dentistry in day to day dental practice-perception of postgraduate dental students and clinical practitioners-KAP study. J Adv Med Med Res. 2016;16(9):1-7. doi: 10.9734/BJMMR/2016/26889.

28. Madhavji A, Araujo EA, Kim KB, Buschang PH. Attitudes, awareness, and barriers toward evidence-based practice in orthodontics. Am J Orthod Dentofacial Orthop. 2011;140(3): 309-16.e2. doi: 10.1016/j.ajodo.2010.05.023. [PubMed: 21889075].

29. Kumar JK, Patthi B, Singla A, Gupta R, Prasad M, Dhama K. Knowledge and usage of evidence based practice among dentists in Modinagar city: a questionnaire based study. $J$ Indian Assoc Public Health Dent. 2017;15(2):170-6. doi: 10.4103/jiaphd.jiaphd_206_16.

30. Kalavani A, Kazerani M, Shekofteh M. Evaluation of SBMU residents' knowledge and use of evidence-based medical databases and concepts. J Payavard Salamat. 2018;12(1):34-43.
31. Dehghani M, Bidar M, Movahhed T. Evaluation of awareness, knowledge and attitude towards evidence-based dentistry among dental students of Mashhad University of Medical Sciences. J Mashhad Dent Sch. 2015;40(1):47-58.

32. Hachesu PR, Gavgani VZ, Salahzadeh Z, Ehteshami A, Piri Z Kasaei M, et al. A study of resident's attitude, knowledge and barriers towards the use of evidence based medicine. Int J Health Syst Disaster Manag. 2013;1(1):38-42. doi: 10.4103/2347-9019.122456.

33. Salehifar D, Lotfi R, Mehrpour G, Vaezi AA, Zamani SH, Tajbakhsh R, Tahmtani T. Assessment of knowledge, attitudes and practice of clinical faculty members of Alborz university of medical sciences towards evidence based medicine (EBM) and its using. Alborz Univ Med J. 2017,6(2):114-22. doi: 10.18869/acadpub.aums.6.2.114.

34. Sadeghi M, Khanjani N, Motamedi F. Knowledge, attitude and application of evidence based medicine (EBM) among residents of Kerman medical sciences university. Iran $J$ Epidemiol. 2011;7(3):20-6.

35. Khami MR, Jafari A, Mohtashamrad Z, Yazdani R, Moscowchi A, Akhgari E, et al. Awareness, knowledge and attitude of dental students of Tehran and Shahid Beheshti Universities of Medical Sciences about evidence-based dentistry. J Islam Dent Assoc Iran. 2012;24(4):197-203.

36. Barzkar F, Baradaran HR, Koohpayehzadeh J. Knowledge, attitudes and practice of physicians toward evidence-based medicine: a systematic review. J Evid Based Med. 2018; 11(4):246-51. doi: 10.1111/jebm.12325. [PubMed: 30430759].

37. Marvei Milan A, Vatanpour M, SHahsavari F. Evaluation of instruction effect on evidence-based dentistry (EBD) knowledge, attitudes, access and confidence and its consistency among dental students of Tehran dental branch, Islamic Azad University in 2017. J Res Dent Sci. 2018; 15(3):136-44. doi: 10.29252/jrds.15.3.3.

38. Davoodi R, Badiee Aval S, Salehi M, Rahmani S, Sabouri G, Soltanifar A, et al. evidence-based medicine: studying the attitude of medical residents in Mashhad. J Patient Saf Qual Improv. 2015;3(1):188-92.

39. Moeintaghavi A, Mokhtari MR, Lal Alizadeh F, Farazi F, Sohrabi M. Evaluation of evidence based dentistry knowledge and usage among postgraduate dental students of Mashhad dental school in 2012-2013. J Mashhad Dent Sch. 2014;38(1):61-70. 